\title{
Electrochemical Effect of Copper Gleam Additives during Copper Electrodeposition
}

\author{
Eden May Dela Pena ${ }^{1,2}$, Sudipta Roy (FIMF) ${ }^{1}$ \\ ${ }^{1}$ School of Chemical and Process Engineering, University of Strathclyde, James Weir \\ building, Glasgow G1 1XJ, United Kingdom \\ ${ }^{2}$ Department of Mining, Metallurgical and Materials Engineering, University of the \\ Philippines Diliman Quezon City 1101 Philippines
}

\begin{abstract}
Electrochemical nano and micro fabrication by Flow and Chemistry is a maskless micropatterning technology that uses an acid-free and low ion concentration electrolyte. However, the effects of additives on the electrochemical behaviour of this type of electrolyte are still unknown; hence, their role during micro- and nano-fabrication is unpredictable. This study reports the effect of a suppressor (Copper Gleam B), an accelerator (Copper Gleam A) and a promoter $\left(\mathrm{Cl}^{-}\right)$on the electrochemical behaviour of copper reduction. The three additives, when employed separately, were found to increase cathode polarisation. The combination of Copper Gleam $\mathrm{B}$ and $\mathrm{Cl}^{-}$showed strong inhibition, particularly in the diffusion-limited region. The addition of Copper Gleam A to the Copper Gleam B- $\mathrm{Cl}^{-}$mix increased the limiting current and suggested plating acceleration. These effects are interpreted in terms of the adsorption-desorption behaviour of the additives on the cathode surface.
\end{abstract}

Keywords: copper plating, additives, Copper Gleam, polarisation, EnFACE

\subsection{Introduction}

Copper electroplating plays an important role in the electronics industry [1]. Electroplating is a key step in the Damascene process that is commonly used to fabricate the fine copper metallisation and interconnects found in semiconductor devices [2]. Similarly, electroplating is used to make copper patterns in the printed circuit boards (PCBs). These copper lines serve as electrical channels that connect one micro-component to the next.

A key to the success of the electroplating process in electronics application is the plating additive. Additives enabled 'superfilling' in interconnect application. Superfilling 
describes the process in which metal deposition proceeds at the bottom of a trench and gradually progresses to the top. Consequently, recessed regions are filled without creating seams and voids within the plated structure [3-9]. Additives are also used for conformal plating of vias and through-holes in PCBs [10]. Conformal plating ensures uniform copper thickness in these areas for reliable electrical conduction.

In the past decade the Electrochemical nano and micro fabrication by Flow and Chemistry (EnFACE) process, developed by Roy et al. [11-15] has offered the possibility of mask-less deposition and dissolution of fine copper lines. The EnFACE electrolyte chemistry is copper sulfate-based, containing low copper salt concentration, acid-free and additive-free. However, the effects of additives on the electrochemical behaviour of the EnFACE electrolyte are still unknown; therefore their role during micro- and nano-fabrication is unpredictable.

Past studies have elucidated the role of additives in superfilling [15-18] and PCB [1922] copper plating. The fundamental combination of superfilling additives is based on a mixture of a suppressor and accelerator [1]. Suppressors are usually polyalkylene glycol (PAG) polymers with molecular weight of at least 2000; such as polyethylene glycol (PEG) $[23,24]$. Suppressors limit metal deposition when adsorbed at the copper surface and create macro-leveling [25]. Accelerators are typically propane sulfonic acids, such as bis (3sulfopropyl) disulfide (SPS) and 3-mercapto-1-propanesulfonate (MPS) [26]. Chloride ions $\left(\mathrm{Cl}^{-}\right)$, when added as a promoter, can enhance the suppressing or the accelerating effect of other additives such as PEG and SPS [23, 27-28].

A popular commercial additive is a Copper Gleam series manufactured by Rohm Haas. Copper Gleam consists of different additives, likely a combination of suppressors, accelerators and promoters, with each one imparting a specific set of attributes to the copper deposit. This additive has found acceptance in the plating industry, and a number of studies have also used this product to investigate the effect of additives on plating baths [29-31]. Recently, Dela Pena et al. [31] noted the reduction of grain size, the increase of yield and tensile strength, and the reduction of ductility and conductivity in copper films after using Copper Gleam in a low copper concentration electrolyte. Although the Copper Gleam system seems to have a similar suppressor-promoter profile, the roles of the individual components has not been analysed. 
The primary aim of this study was to understand the fundamental action of Copper Gleam in the electrolyte used for maskless process (EnFACE). The EnFACE electrolyte is acid-free and has low concentration of $\mathrm{Cu}$ salt $(0.1 \mathrm{M} \mathrm{CuSO} 4)$. Cathodic polarisation experiments, using the classic three-electrode electrochemical apparatus, were performed on the additive-free and additive-containing EnFACE electrolytes to reveal the mechanism of additive action during plating. This paper, hence, is the first to report on the electrochemical behaviour of Copper Gleam and $\mathrm{Cl}^{-}$additives in acid-free electrolytes containing low metal ion concentration.

\subsection{Experimental}

\subsection{Apparatus}

Potentiodynamic experiments were performed using the three-electrode apparatus. The working electrode was a $0.5 \mathrm{~mm}$ diameter copper rod encased in epoxy, with only the end exposed. The counter electrode was a $25 \mathrm{~cm}^{2}$ copper sheet. The reference electrode was $\mathrm{Ag} / \mathrm{AgCl} / \mathrm{Sat}$. $\mathrm{KCl}\left(+0.197 \mathrm{~V}_{\mathrm{SHE}}\right)$ inserted in a luggin capillary. Measurements were done using an Autolab potentiostat (PGSTAT101) and data analysed using the NOVA 1.7 software. Mechanical stirring was not performed during the polarisation tests.

\subsection{Chemicals}

Technical grade $\mathrm{CuSO}_{4}$ and $\mathrm{H}_{2} \mathrm{SO}_{4}$ were used for preparing the plating electrolytes. The additives used were Copper gleam HS - 200 A (accelerator) and B (suppressor) from Rohm Haas, and $\mathrm{Cl}^{-}$were sourced from concentrated $\mathrm{HCl}$ (37\% $\mathrm{HCl}$ Sigma Aldrich). The compositions of the additive-free and additive-containing electrolytes are presented in Table 1. The additive-free EnFACE electrolyte consisted of $0.1 \mathrm{M} \mathrm{CuSO}_{4}$ solution. The standard electrolyte composition was obtained from industry recommended values [32]. The data for polarisation was interpreted against the standard.

The superfilling additives tested were Copper Gleam B, Copper Gleam A, and $\mathrm{Cl}^{-}$. The amount of additives used in the tests is based on the manufacturer- recommended dosage consisting of $10 \mathrm{~g} / \mathrm{L}$ Copper Gleam B, $0.5 \mathrm{~g} / \mathrm{L}$ Copper Gleam A, and 70 ppm $\mathrm{Cl}^{-}$. Therefore, all calculations of percent dosages (i.e. 17, 33, 50,100 and 200\%) were based on the recommended values. For example, a 33\% single-additive $\mathrm{Cl}^{-}$concentration (Cl-33) needed 
$23.1 \mathrm{ppm} \mathrm{Cl}^{-}$in the bath; or a 50\% triple-additive concentration in the EnFACE electrolyte (E-50) required $5 \mathrm{~g} / \mathrm{L}$ Copper Gleam B, $0.25 \mathrm{~g} / \mathrm{L}$ Copper Gleam A, and $35 \mathrm{ppm} \mathrm{Cl}^{-}$.

\subsection{Procedure}

Prior to each test, the working electrode was polished using 4000 grit SiC. The polished copper rod was washed with ethanol and air dried. The electrolyte was poured into the bath chamber, and the three electrodes were immersed in the solution. Polarisation measurements were then performed accordingly at a scan rate was $0.002 \mathrm{Vs}^{-1}$ and over the cathodic potential range of $0 \mathrm{~V}$ to $-1.0 \mathrm{~V}$.

Three sets of polarisation experiments were conducted. The first set compared cathode polarisation in the standard (S) and the EnFACE (E) electrolytes. The second set investigated the effect of different concentrations of single additives on the polarisation behaviour in the EnFACE bath. In the third set, the effect of different concentrations of the multi-additive mixtures (i.e. Copper Gleam B- $\mathrm{Cl}^{-}$and Copper Gleam B-Cl-Copper Gleam A) were studied.

\subsection{Results and Discussion}

\subsection{Standard Copper vs EnFACE Bath}

Figure 1 presents the current density-potential (i-V) curve of the additive-free standard copper (S-0) electrolyte with the EnFACE (E-0) electrolyte. Figure 1a shows the plots over the potential range of 0 to $-1.0 \mathrm{~V}_{\mathrm{Ag} / \mathrm{AgCl}}$; Figure $1 \mathrm{~b}$ presents a close-up view of the curves at potentials 0 to $-0.2 \mathrm{~V} \mathrm{Ag} / \mathrm{AgCl}$ to show details in this potential range.

The S-0 electrolyte has the characteristic sigmoidal shape that contained the typical charge-transfer, mixed control, and limiting current regions in the cathodic polarisation curves. In contrast, the polarisation curve of E-0 has a very small charge-transfer region, due to the early appearance of the mass transfer limited current.

The absence of an inflection point characteristic of hydrogen evolution (HE) in the curve of E-0 suggests that $\mathrm{HE}$ occurred at potentials beyond $-1.0 \mathrm{~V}_{\mathrm{Ag} / \mathrm{AgCl}}$. In the $\mathrm{S}-0$ electrolyte, $\mathrm{HE}$ was observed at about $-0.8 \mathrm{~V} \mathrm{Ag} / \mathrm{AgCl}$. Hydrogen evolution can proceed through the reduction of $\mathrm{H}^{+}$or the breakdown of water, and the dominant reaction route depends on 
$\mathrm{pH}$. In neutral solutions, hydrogen is produced from the decomposition of water; at potentials more negative than $-0.6 \mathrm{~V} \mathrm{Ag} / \mathrm{AgCl}$ [33]. In acidic solutions, hydrogen is produced via the reduction of $\mathrm{H}^{+}$and is expected to occur at potentials less negative than $-0.6 \mathrm{~V}_{\mathrm{Ag} / \mathrm{AgCl}}$, in agreement with the current study.

The mass transfer limiting currents, $i_{\text {Lim }}$, for S-0 and E-0 are listed in Table 2, and shows that the $i_{\text {Lim }}$ of E- 0 is about $75 \%$ lower than the $i_{\text {Lim }}$ of S- 0 . The $i_{\text {Lim }}$ for copper deposition from an acid-containing electrolyte such as S-0, $i_{L, S-0}$, and an acid-free electrolyte such as E-0, $i_{L, E-0}$, may be expressed by:

$$
\begin{array}{r}
i_{L, S-0}=n F D \frac{C_{C u, S-0}}{\delta} \\
i_{L, E-0}=n F D \frac{C_{C u, E-0}}{\delta\left(1-t_{+}\right)}
\end{array}
$$

where $n$ is the oxidation number of $\mathrm{Cu}, F$ is the Faradays number, $D$ is diffusivity of $\mathrm{Cu}$ in the electrolyte, $C_{C u}$ is the concentration of $\mathrm{Cu}^{2+}, \delta$ is the thickness of the Nernst diffusion layer, and $t_{+}$is the ion transport or transference number of the $\mathrm{Cu}$ cation, which needs to be taken into account due to the low conductivity of the solution.

Assuming that the diffusion layer for $\mathrm{Cu}^{2+}$ is similar in the two electrolytes, then (1) and (2) transforms to:

$$
\frac{i_{L, S-0}}{i_{L, E-0}}=\frac{C_{C u, S-0}}{C_{C u, E-0}}\left(1-t_{C u}\right)
$$

Using the concentration of $\mathrm{Cu}^{2+}$ in the two electrolytes and the ion transport number of $\mathrm{Cu}^{2+}$ in the EnFACE electrolyte $\left(\mathrm{t}_{+}=0.358\right.$; [34]) the theoretical ratio of the limiting currents is equal to 4.04. On the other hand, the values shown in Table 2 yields an experimental value of the ratio equal to 3.92 , which is similar to the calculated theoretical value. This proves that the polarisation behaviour of the EnFACE electrolyte is primarily influenced by the low concentration of $\mathrm{Cu}^{2+}$.

\subsection{Effect of Single Additive}

Figure 2a shows the effect of different amounts of $\mathrm{Cl}^{-}$ions on cathode polarisation in the EnFACE electrolyte. The i-V curves of the $\mathrm{Cl}^{-}$-containing electrolytes lacked the chargetransfer region and started at the mixed-control region. $\mathrm{Cl}^{-}$shifted the curves to lower $i$ both 
in the mixed-control and $i_{\text {Lim }}$ regions, indicating plating inhibition. The degree of inhibition progressively increased with increasing amounts of $\mathrm{Cl}^{-}$, suggesting concentration-dependent polarisation in the electrolyte.

Past studies reported the ability of $\mathrm{Cl}^{-}$to increase cathode polarisation in copper electrolytes [33, 35-37]. Soares et al. [37] proposed that this is due to the formation of a passive layer of $\mathrm{CuCl}$ at the cathode when the $\mathrm{Cu}^{2+}$ concentration of the electrolyte exceeds $1 \mathrm{mM}$. The recommended $\mathrm{Cl}^{-}$concentration used in this study is about $2 \mathrm{mM}$; thus, it is conceivable that the formation of the said $\mathrm{CuCl}$ film caused the observed polarisation.

Figure $2 \mathrm{~b}$ shows the effect of varying amounts of Copper Gleam B on cathodic polarisation in the ENFACE plating electrolyte. As the amount of Gleam B was increased, the polarisation curves shifted to lower $i$ and more negative potentials; again indicative of plating inhibition. Similarly, inhibition was found to be strongly concentration-dependent, with maximum polarisation occurring at the highest additive concentration. The chargetransfer region became prominent in the cathodic potential range after the addition of Copper Gleam B. Furthermore, the mixed control region was extended over a larger potential range. For example, in GB-100 the mixed control region existed from $-0.25 \mathrm{~V}_{\mathrm{Ag} / \mathrm{AgCl}}$ to $-0.5 \mathrm{~V} \mathrm{Ag} / \mathrm{AgCl}$, occurring over a range of about $0.25 \mathrm{~V}$. For the EnFACE electrolyte, the charge-transfer region was missing and the mixed-control region occurred from about 0 to $-0.18 \mathrm{~V} \mathrm{Ag} / \mathrm{AgCl}, \mathrm{a}$ range of only $0.18 \mathrm{~V}$. The $i_{\text {Lim }}$ value was modestly reduced by using low amounts of Copper Gleam B; at higher additive concentrations, the $i_{\text {Lim }}$ assumed a fairly constant value.

The results indicate that Copper Gleam $\mathrm{B}$ is a strong polariser in the EnFACE electrolyte. While we can only speculate on the actual chemical components of Copper Gleam B, it is likely that Copper Gleam B would be a large organic molecule of high molecular weight like PEG. The strong inhibiting effect of PEG in the conventional acidcopper electrolyte is well known [23, 38-39]. Suppressors are known to affect the chargetransfer mechanisms more than the diffusion-controlled ones [27, 38]. This explains the appearance of the charge-transfer region in the polarisation plots after adding Copper Gleam $\mathrm{B}$ in the electrolyte.

Figure $2 \mathrm{c}$ shows the polarisation behaviour of the EnFACE electrolyte with different concentrations of Copper Gleam A. Again, the charge transfer region of the i-V curve was missing, and only the mixed-control and $i_{\text {Lim }}$ region were present. No significant shift in the polarisation curve was observed at low concentrations of Copper Gleam A (e.g GA-17 and 
GA-33). However, at higher Gleam A concentrations, the curve shifted to lower $i$ that indicated plating inhibition. Both the mixed-control and $i_{\text {Lim }}$ regions were changed, although the latter exhibited a greater shift. Inhibition was also found to be concentration-dependent, similar to those seen in Cl- and Copper Gleam B.

The inhibiting effect of Copper Gleam A is somewhat surprising as accelerators are expected to depolarise the cathode [24]. However, Tan et al. [40] reported similar concentration-dependent inhibiting behaviour for the accelerator SPS when used as the lone additive in the conventional acid-copper sulfate electrolyte. They explained that suppression was the result of the $\mathrm{Cu}(\mathrm{I})$-thiolate complex present at the cathode. It is therefore probable that similar mechanisms are at play in the Copper Gleam A-containing EnFACE electrolyte.

The single additives also inhibited hydrogen evolution (HE). In the E-0 electrolyte, $\mathrm{HE}$ commenced at potentials greater than $-0.4 \mathrm{~V} \mathrm{Ag} / \mathrm{AgCl}$. In the additive-containing electrolyte, the increase in $\mathrm{HE}$ current started at about $-0.8 \mathrm{~V} \mathrm{Ag} / \mathrm{AgCl}$.

Figure 3 presents the cathodic polarisation of the EnFACE plating electrolyte before and after addition of $\mathrm{Cl}^{-}$, Copper Gleam B and Copper Gleam A. When added separately the three additives caused cathode polarisation in the EnFACE electrolyte. However, the degree of polarisation or inhibition, which is judged from the amount of shift to lower $i$ and higher potentials, depends on the type of additive. Copper Gleam A and $\mathrm{Cl}^{-}$created similar though modest levels of inhibition. Copper Gleam B caused significant polarisation, especially at the charge-transfer regions.

The strong inhibition seen in Copper Gleam B may be linked to the degree of adsorption and consequent surface coverage of the cathode by the additives. A larger molecule can cover a bigger surface and cause greater suppression. The molecules of Copper Gleam B is believed to be relatively larger compared to the molecules of Copper Gleam A and $\mathrm{Cl}^{-}$, as would be if one were a PEG-type and the other an SPS type-additive. Interestingly, the $i_{\text {Lim }}$ in the electrolytes with single additive were similar. This suggests that $i_{\text {Lim }}$ is independent of the type of additive used. The steady value of the $i_{\text {Lim }}$ may be caused by mass transport-limited reduction of $\mathrm{Cu}^{2+}$. Finally, the additives increased the hydrogen overpotential and hydrogen evolution occurred at a higher potential. 


\subsection{Effect of mixed additive}

\subsubsection{Cl-Copper Gleam B}

Figure 4 shows the cathodic polarisation curve for the EnFACE plating electrolyte with additions of $\mathrm{Cl}^{-}$, Copper Gleam B, and Cl-Copper Gleam B, all at industry recommended concentrations. The GB-100 and Cl-GB plots were quite similar, displaying the full sigmoidal shape of the curve. The charge-transfer region of the GB-100 and Cl-GB electrolyte did not have significant difference (Fig. 4b). At the mixed control and the $i_{\text {Lim }}$ region, the Cl-GB plot shifted to lower $i$ values. To illustrate, Cl-GB electrolyte has an $i_{\text {Lim }}$ of about $3.0 \mathrm{~mA} \cdot \mathrm{cm}^{-2}$, while the GB-100 and Cl-100 electrolytes have $i_{\text {Lim }}$ of $5.0 \mathrm{~mA} \cdot \mathrm{cm}^{-2}$. This indicates that a further increase in plating suppression occurred after the two additives were combined, and confirms the synergistic effect of $\mathrm{Cl}^{-}$and Copper Gleam B on plating suppression.

The current results are consistent with past studies that observed the strong plating inhibition caused by the combination of a suppressor (PEG) and a promoter $\left(\mathrm{Cl}^{-}\right)[7,9,41$, 42]. Using the PEG model, studies suggest that inhibition was due to the presence of the PEG- $\mathrm{Cu}^{+}-\mathrm{Cl}^{-}$complex at the cathode [43-44]. Feng et al. [45] proposed that $\mathrm{Cl}^{-}$acts as a strong anchor and secures the PEG-Cu${ }^{+}$complex to the cathode surface. Hai et al. [46] further suggested that the PEG branches could interlink creating a large network of interlinked suppressor complex that effectively covers a huge area of the substrate surface.

\subsubsection{Cl-Copper Gleam B-Copper Gleam A}

The effect of combining all three additives; i.e. $\mathrm{Cl}^{-}$, Copper Gleam $\mathrm{B}$, and Copper Gleam A, on cathodic polarisation of the EnFACE electrolyte is shown in Fig. 5. Figure 5a shows the plot over the potential range 0 to $-1.0 \mathrm{~V}_{\mathrm{Ag} / \mathrm{AgCl}}$, while Fig. $5 \mathrm{~b}$ shows the curve over the range 0 to $-0.3 \mathrm{~V}_{\mathrm{Ag} / \mathrm{AgCl}}$. It was seen earlier that the mixture of $\mathrm{Cl}^{-}$and Copper Gleam $\mathrm{B}$ electrolyte caused synergistic inhibition at the diffusion-limited regions. However, an interesting phenomenon was seen with the addition of the accelerator, Copper Gleam A, to the Cl-GB electrolyte. While the charge-transfer region appeared unaffected, the mixed control and $i_{\text {Lim }}$ region were found shifted to higher current densities. The upward shift in the $\mathrm{i}-\mathrm{V}$ curve suggests that Copper Gleam A caused plating acceleration in the mass-transport region. 
The accelerating effect of Copper Gleam A, when used with Copper Gleam B and $\mathrm{Cl}^{-}$ that was seen in the EnFACE electrolyte is similar to those reported when SPS is added to PEG-Cl--containing conventional copper electrolytes [40, 45, 47]. It is believed that the accelerator SPS reacts with $\mathrm{CuCl}$ to form the $\mathrm{Cu}(\mathrm{I})$ thiolate molecule [48]. The thiolate molecule is known to weaken the suppressing effect of the $\mathrm{PEG}-\mathrm{Cl}^{-}-\mathrm{Cu}$ complex at the cathode surface; either (i) by directly competing with the suppressor for the $\mathrm{Cu}$ ion, or (ii) by weakening the bond between the suppressor and the cathode surface. While it is likely that similar mechanisms caused the acceleration observed in the EnFACE electrolyte, other explanations are also possible. However, a definitive mechanism would require further work. On the other hand, the observed increase in limiting current density, though somewhat unexpected, could be explained by (i) the reduction of the concentration of suppressors (Copper Gleam $\mathrm{A}-\mathrm{Cl}^{-}$) at the surface due to the action of the accelerator (Copper Gleam B); or (ii) by a change in the electrode's surface morphology during the polarisation test.

Figure 6 shows the polarisation curves for different concentrations of the mixed ClCopper Gleam B-Copper Gleam A in the plating electrolyte. As the amount of additives was increased, the curves shifted to more negative $\eta$ values and lower values of $i$ in both the charge- transfer and diffusion-limited regions. Similar to what was previously observed in earlier electrolytes, this result indicated concentration-dependent plating inhibition. However, beyond the recommended concentrations no appreciable increase in plating inhibition was observed, as suggested by the similar i-V curves of E-100 and E-200.

The results indicate that plating inhibition was dependent on the amount of additives used. This concentration-dependent suppression is logical because higher amounts of additives in the electrolyte correlate to more molecules being adsorbed at the cathode. However, it appears that plating suppression reached a maximum after a certain amount of additive was used. This occurred at the $100 \%$ additive concentration, and no appreciable cathode polarisation was observed beyond this value. This result is consistent with the 'polarisation plateau' reported for additive-containing electrolytes [7].

The electrochemical behaviour of the EnFACE electrolyte with additives is similar to that of a standard $\mathrm{Cu}$ plating bath. The suppression and acceleration phenomenon accompanying the use of additives were all observed in the EnFACE. This implies that the EnFACE electrolyte could behave similarly and give comparable results as the standard 
electrolyte when used in actual service. On the other hand, the inherently low limiting current of the EnFACE electrolyte could be a disadvantage, since this leads to lower plating rates.

\subsection{Conclusion}

Copper Gleam B, Copper Gleam A and $\mathrm{Cl}^{-}$, when used separately, induced a concentration-dependent polarisation of the cathode in the EnFACE electrolyte. The increase in polarisation indicated plating inhibition. Plating inhibition was probably due to the adsorption of additives at the cathode surface. The adsorbed additives had a two-fold effect on plating: i) adversely influenced the interfacial charge-transfer rate of $\mathrm{Cu}^{2+}$ and ii) prevented $\mathrm{Cu}^{2+}$ from reaching the cathode by covering active surfaces.

A synergistic effect on plating inhibition in the mass-transport limited regions occurred when a mixture of Copper Gleam B and $\mathrm{Cl}^{-}$was used. Furthermore, the accelerating effect of Copper Gleam A was revealed when added to the Copper Gleam B-Cl- containing EnFACE electrolyte.

In the presence of additives, the electrochemical behaviour of the EnFACE bath is parallel to that of the standard copper electrolyte. However, the EnFACE electrolyte showed lower limiting current and higher polarisation than a standard bath due to its high resistivity, which would consequently limit the plating rates in the EnFACE process. Such could have implications on the properties of the copper produced from the additive-containing EnFACE electrolyte. 


\section{References:}

[1] P.C. Andricacos, C. Uzoh, J.C. Dukovic, J. Horkans and H. Deligiani. IBM J. Res. Dev., 1998,$42 ; 567$.

[2] S. Franssila. 2010, $2^{\text {nd }}$ Edition, John Wiley \& Sons Ltd, West Sussex, United Kingdom.

[3] A. Brenner. 1963, Academic Press, New York.

[4] S.S. Kruglikov, N.T. Kudriavtsev, G.F. Vorobiova and A. Ya. Antonov. Electrochim. Acta, 1965, 10; 253-261.

[5] G. Fabricus and G. Sundholm. J. of Appl. Electrochem., 1985, 15; 797 - 801.

[6] T.C. Franklin, Surf. and Coating Tech., 1987, 30; 415 - 428.

[7] L. Oniciu and L. Muresan. J. of Appl. Electrochem., 1991, 21(7); 565-574.

[8] E. Michailova, I. Vitanova, D. Stoychev and A. Milchev. Electrochim. Acta, 1993, $38(16) ; 2455-2458$.

[9] J.J. Kelly, C. Tian and A.C. West. J. of Electrochem. Soc., 1998, 146 (7); 2540 - 2545.

[10] M. Schlesinger and M. Paunovic. 2010, $5^{\text {th }}$ ed. John Wiley and Sons Publication NJ.

[11] S. Nouraei and S. Roy. Electrochim. Acta, 2009, 54; 2444-2449.

[12] S. Roy, Y. Gupte and T.A. Green. Chem. Engg. Sci., 2001, 56; 5025-5035.

[13] I. Schonenberger and S. Roy. Electrochim. Acta, 2005, 51; 809-819.

[14] T. Widayatno and S. Roy. J. of Appl. Electrochem, 2014, 44(7); 807-820.

[15] S. Coleman and S. Roy. J. of Appl. Electrochem, 2015, 45(8); 889-898.

[16] U. Landau. 1982, Plenum Press New York.

[17] L.N. Schoenberg. J. Electrochem. Soc., 1971, 118(70); 1571-1576.

[18] M. Paunovic and R. Arndt. J. Electrochem. Soc., 1983, 130; 794-799.

[19] A.J. Cobley and D.R. Gabe. Circuit World, 2003, 29(4); 11-18.

[20] E.K. Yung, L.T. Romankiw and R.C. Alkire. J. Electrochem. Soc., 1989, 136(1); 206215.

[21] J.J. Kelly, C. Tian and A.C. West. J. Electrochem. Soc., 1999, 146; 2540.

[22] J.P. Healy, D. Pletcher and M. Goodenough. J. Electroanal. Chem., 1992, 338(1-2); 179.

[23] M.R.H. Hill and G.T. Rogers. J. Electroanal. Chem., 1978, 86; 179-188.

[24] J.P. Healy and D. Pletcher. J. Electroanal. Chem., 1992, 338; 155-165. 
[25] H-M Chen, S.J. Parulekar and A. Zdunek. J. of the Electrochem. Soc., 2008, 155(5); D341 - D348.

[26] K. Kondo, T. Matsumoto and K. Watanabe. J. Electrochem. Soc., 2004, 151(4); C250$\mathrm{C} 255$.

[27] P. Broekmann, A. Fluegel, C. Emnet, M. Arnold, C. Roeger - Goepfert, A. Wagner, N.T.M. Hai and D. Mayer. Electochim. Acta, 2011, 56; $4724-4734$.

[28] E. Garcia-Cardona, E.H. Wong and D.P. Barkey. J. Electrochem. Soc., 2011, 158;D143 $-\mathrm{D} 148$.

[29] S. Roy and P.N. Pintauro. J. Electrochem.Soc., 1993, 140(11); 3167-3175.

[30] A. Tzanavaras, G. Young and S. Gleixner. J. Electrochem. Soc., 2005, 152(2); C101$\mathrm{C} 107$

[31] E.M. Dela Pena, N. Bains, A. Hussain, A. Cobley and S. Roy. Inst. of Matls. Finish., 2015, 19(6); 288-293.

[32] Rohm and Haas. 2007, Electronic Materials: Circuit Board Technologies.

[33] Y.L. Kao, K.C. Li, G.C. Tu and A.C. Huang. The Electrochem. Soc., 2005, 152 (9); C605- C611.

[34] R. Taft and H.E. Messmore. J. Phys. Chem., 1931, 35; 2585.

[35] D.N. Upadhyay and V. Yegnaraman. Mater. Chem. Phys., 2000, 62; 247.

[36] M.H. Holzle, C.W. Apsel, T. Will and D.M. Kolb. J. Electrochem. Soc., 1995, 142; 3741 .

[37] D.M. Soares, S. Wasle, K.G. Weil, and K. Doblhofer. J. Electroanal. Chem., 2002, 532; 353-358.

[38] M. Yokoi, S. Konishi and T. Hayashi. Denki Kagaku, 1984, 52; 218-223.

[39] Y. Jin, K. Kondo, Y. Suzuki, T. Matsumoto and D.P. Barkey. Electrochem. Solid State, 2005, 8; C6-C8.

[40] M. Tan, C. Guymon, D. Wheeler and J. Harb. J. Electrochem. Soc., 2007, 154(2); D78D81.

[41] M. Kang and A. Gewirth. J. of the Electrochem. Soc., 2003, 150(6); C426-C434.

[42] J.P. Healy, D. Pletcher and M. Goodenough. J. Electroanal. Chem., 1992, 338(1); 155.

[43] Q. Chen, Z. Wang, J. Cai and L. Liu. Microelectronic Engg., 2010, 87(3); 527 - 531.

[44] K. Kondo, N. Yamakawa, Z. Tanaka and K. Hayashi K. J. Electroanal. Chem., 2003, $559 ; 137$.

[45] Z.V. Feng, X. Li, A.A. Gewirth. J. Phys. Chem. B, 2003, 107(35); 9415-9423. 
[46] N.T.M. Hai, T.T.M. Huynh, A. Fluegel, M. Arnold, D. Mayer, W. Reckien, T. Bredow and P. Broekmann. Electrochim. Acta, 2012, 70; 286.

[47] M. Hasegawa, Y. Negishi, T. Nakanishi and T. Osaka. J. Electrochem. Soc., 2005, 152(4); C221-C228. 


\section{Figure Captions}

Figure 1: Comparison of polarisation curves of the Enface electrolyte (E-0) and standard copper electrolyte (S-0), both without additives. (a) Plot in the overpotential range of 0 to $1.0 \mathrm{~V} \mathrm{Ag} / \mathrm{AgCl}$ and (b) inset, zoomed in at 0 to $-0.2 \mathrm{~V} \mathrm{Ag} / \mathrm{AgCl}$.

Figure 2: Cathodic polarisation curve for the EnFACE electrolyte without additives (E-0), and with different concentrations of single additives (a) $\mathrm{Cl}^{-}$(b) Copper Gleam B and (c) Copper Gleam A. Labels involving 17, 33, 50 and 100 refer to relative percentage with respect to the recommended dosage.

Figure 3. Cathodic polarisation curves of the EnFACE plating electrolyte i) without additives (E-0), and with single additives at recommended concentrations: ii) Copper Gleam B (GB100), iii) Copper Gleam A (GA-100) and iv) $\mathrm{Cl}^{-}(\mathrm{Cl}-100)$.

Figure 4: Cathodic polarisation curves of the Enface electrolyte: i) without additives (E-0),ii) with single additives Cl- (Cl-100) and Copper Gleam B (GB-100) at industry recommended dosages, and iii) with mixed Cl- and Copper Gleam B (Cl-GB). a) Plot showing potential range from 0 to $-1 \mathrm{VAg} / \mathrm{AgCl}$ and $\mathrm{b}$ ) inset, from 0 to $-0.3 \mathrm{VAg} / \mathrm{AgCl}$.

Figure 5: Cathodic polarisation curve of the EnFACE plating electrolyte: i) without additive (E-0), ii) with copper gleam B (GB-100), iii) with a mixture of $\mathrm{Cl}$ and Copper Gleam B (ClGB), and iv) with recommended concentrations of Cl-, Copper Gleam B and Gleam A (ClGB-GA). a) Plot showing overpotential range from 0 to $-1.0 \mathrm{VAg} / \mathrm{AgCl}$ and $\mathrm{b}$ ) inset, at overpotential range of 0 to $-0.3 \mathrm{VAg} / \mathrm{AgCl}$.

Figure 6: Cathodic polarisation curve of the EnFACE electrolyte with different concentrations of the mixed additives $\mathrm{Cl}^{-}$, Copper Gleam A, and Copper Gleam B. Labels involving 17, 33, 50 and 100 refer to relative percentage with respect to the recommended dosage of 70 ppm Cl-, 0.5 ml/L Copper gleam A, and 10 ml/L Copper gleam B. 
Table 1: Chemical composition of the tested copper plating electrolytes and nomenclature.

\begin{tabular}{|c|c|c|c|c|c|c|c|}
\hline \multicolumn{2}{|c|}{ Experimental setting } & $\begin{array}{c}\text { Sample } \\
\text { designation }\end{array}$ & $\begin{array}{l}\mathrm{CuSO}_{4} \\
(\mathrm{M})\end{array}$ & $\begin{array}{l}\mathrm{H}_{2} \mathrm{SO}_{4} \\
(\mathrm{ml} / \mathrm{L})\end{array}$ & $\begin{array}{c}\mathrm{HCl} \\
(\mathrm{ppm})\end{array}$ & $\begin{array}{c}\text { Gleam } \\
\text { A } \\
(\mathrm{ml} / \mathrm{L})\end{array}$ & $\begin{array}{c}\text { Gleam } \\
\text { B } \\
(\mathrm{ml} / \mathrm{L})\end{array}$ \\
\hline \multicolumn{2}{|r|}{ Standard electrolyte } & $\mathrm{S}$ & 0.63 & 2.04 & 70 & 0.5 & 10 \\
\hline \multicolumn{2}{|c|}{ Standard electrolyte without additives } & S-0 & 0.63 & 2.04 & $\mathrm{x}$ & $\mathrm{x}$ & $\mathrm{x}$ \\
\hline \multicolumn{2}{|c|}{ EnFACE electrolyte without additives } & E-0 & 0.1 & $\mathrm{x}$ & $\mathrm{x}$ & $\mathrm{x}$ & $\mathrm{x}$ \\
\hline \multicolumn{2}{|c|}{$\begin{array}{l}\text { EnFACE electrolyte with } 100 \% \text { of } \mathrm{Cl}^{-} \text {, Gleam B } \\
\text { additive concentration }\end{array}$} & Cl-GB & 0.1 & $\mathrm{x}$ & 70 & $\mathrm{x}$ & 10 \\
\hline \multirow{4}{*}{ 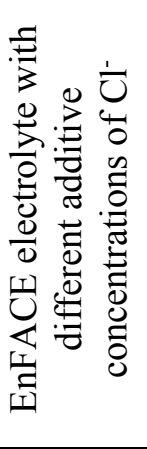 } & $\begin{array}{l}17 \% \text { of the recommended } \mathrm{Cl}^{-} \text {additive } \\
\text { concentration }\end{array}$ & $\mathrm{Cl}-17$ & 0.1 & $\mathrm{x}$ & 12 & $\mathrm{x}$ & $\mathrm{x}$ \\
\hline & $\begin{array}{l}33 \% \text { of the recommended } \mathrm{Cl}^{-} \text {additive } \\
\text { concentration }\end{array}$ & $\mathrm{Cl}-33$ & 0.1 & $\mathrm{x}$ & 23 & $\mathrm{x}$ & $\mathrm{x}$ \\
\hline & $\begin{array}{l}50 \% \text { of the recommended } \mathrm{Cl}^{-} \text {additive } \\
\text { concentration }\end{array}$ & $\mathrm{Cl}-50$ & 0.1 & $\mathrm{x}$ & 35 & $\mathrm{x}$ & $\mathrm{x}$ \\
\hline & $\begin{array}{l}100 \% \text { of the recommended } \mathrm{Cl}^{-} \text {additive } \\
\text { concentration }\end{array}$ & Cl-100 & 0.1 & $\mathrm{x}$ & 70 & $\mathrm{x}$ & $\mathrm{x}$ \\
\hline \multirow{4}{*}{ 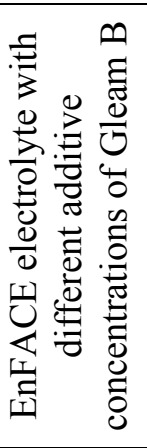 } & $\begin{array}{c}17 \% \text { of the recommended Gleam B } \\
\text { additive concentration }\end{array}$ & GB-17 & 0.1 & $\mathrm{x}$ & $\mathrm{x}$ & $\mathrm{x}$ & 1.7 \\
\hline & $\begin{array}{l}33 \% \text { of the recommended Gleam B } \\
\text { additive concentration }\end{array}$ & GB-33 & 0.1 & $\mathrm{x}$ & $\mathrm{x}$ & $\mathrm{x}$ & 3.3 \\
\hline & $\begin{array}{l}50 \% \text { of the recommended Gleam B } \\
\text { additive concentration }\end{array}$ & GB-50 & 0.1 & $\mathrm{x}$ & $\mathrm{x}$ & $\mathrm{x}$ & 5.0 \\
\hline & $\begin{array}{l}100 \% \text { of the recommended Gleam B } \\
\text { additive concentration }\end{array}$ & GB-100 & 0.1 & $\mathrm{x}$ & $\mathrm{x}$ & $\mathrm{x}$ & 10 \\
\hline \multirow{4}{*}{ 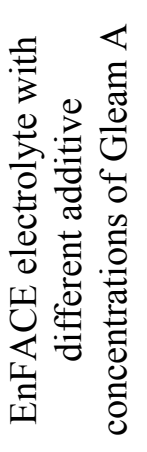 } & $\begin{array}{l}17 \% \text { of the recommended Gleam A } \\
\text { additive concentration }\end{array}$ & GA-17 & 0.1 & $\mathrm{x}$ & $\mathrm{x}$ & 0.09 & $\mathrm{x}$ \\
\hline & $\begin{array}{l}33 \% \text { of the recommended Gleam A } \\
\text { additive concentration }\end{array}$ & GA-33 & 0.1 & $\mathrm{x}$ & $\mathrm{x}$ & 0.17 & $\mathrm{x}$ \\
\hline & $\begin{array}{c}50 \% \text { of the recommended Gleam A } \\
\text { additive concentration }\end{array}$ & GA-50 & 0.1 & $\mathrm{x}$ & $\mathrm{x}$ & 0.25 & $\mathrm{x}$ \\
\hline & $\begin{array}{l}100 \% \text { of the recommended Gleam A } \\
\text { additive concentration }\end{array}$ & GA-100 & 0.1 & $\mathrm{x}$ & $\mathrm{x}$ & 0.50 & $\mathrm{x}$ \\
\hline \multirow{5}{*}{ 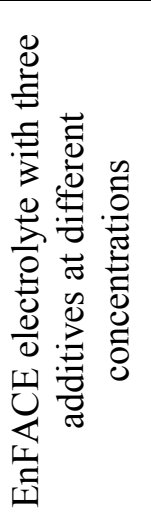 } & $\begin{array}{l}17 \% \text { of the recommended additive } \\
\text { concentration }\end{array}$ & E-17 & 0.1 & $\mathrm{x}$ & 12 & 0.09 & 1.7 \\
\hline & $\begin{array}{l}33 \% \text { of the recommended additive } \\
\text { concentration }\end{array}$ & E-33 & 0.1 & $\mathrm{x}$ & 23 & 0.17 & 3.3 \\
\hline & $\begin{array}{l}50 \% \text { of the recommended additive } \\
\text { concentration }\end{array}$ & E-50 & 0.1 & $\mathrm{x}$ & 35 & 0.25 & 5.0 \\
\hline & $\begin{array}{l}100 \% \text { of the recommended additive } \\
\text { concentration }\end{array}$ & E-100 & 0.1 & $\mathrm{x}$ & 70 & 0.50 & 10 \\
\hline & $\begin{array}{l}200 \% \text { of the recommended additive } \\
\text { concentration }\end{array}$ & E-200 & 0.1 & $\mathrm{x}$ & 140 & 1.00 & 20 \\
\hline
\end{tabular}


Table 2: Mass transfer limiting currents for standard electrolyte without additives (S-0) and EnFACE electrolyte without additives (E-0)

\begin{tabular}{|c|c|}
\hline $\begin{array}{c}\text { Additive } \\
\text { concentration }\end{array}$ & $\begin{array}{c}\text { Limiting current } \\
\left(\mathrm{mA} \cdot \mathrm{cm}^{-2}\right)\end{array}$ \\
\hline E-0 & 5.30 \\
\hline S-0 & 20 \\
\hline
\end{tabular}




\section{Figures}

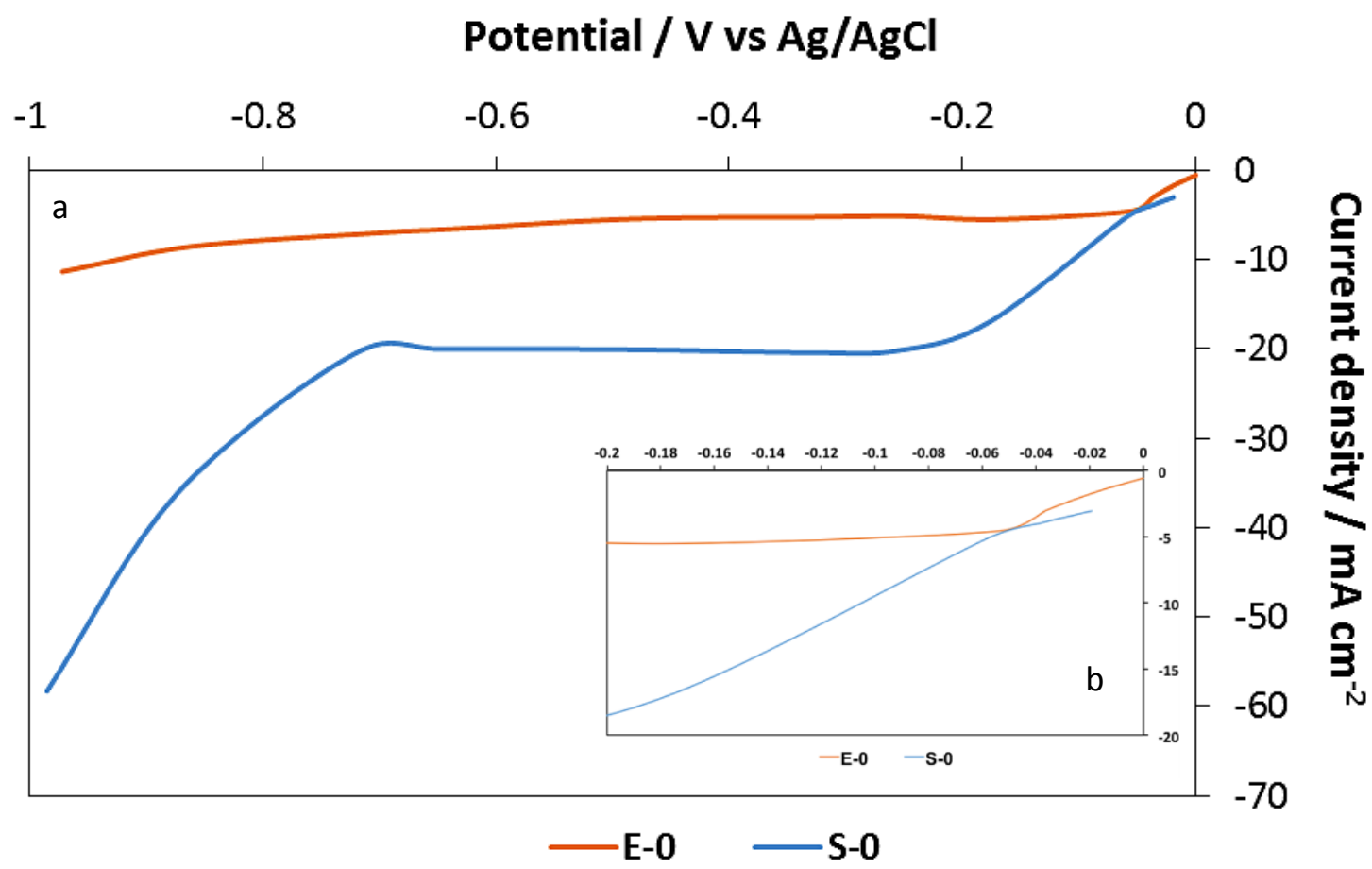

Figure 1: Comparison of polarisation curves of the Enface electrolyte (E-0) and standard copper electrolyte (S-0), both without additives. (a) Plot in the overpotential range of 0 to $1.0 \mathrm{~V} \mathrm{Ag} / \mathrm{AgCl}$ and (b) inset, zoomed in at 0 to $-0.2 \mathrm{~V} \mathrm{Ag/AgCl}$. 

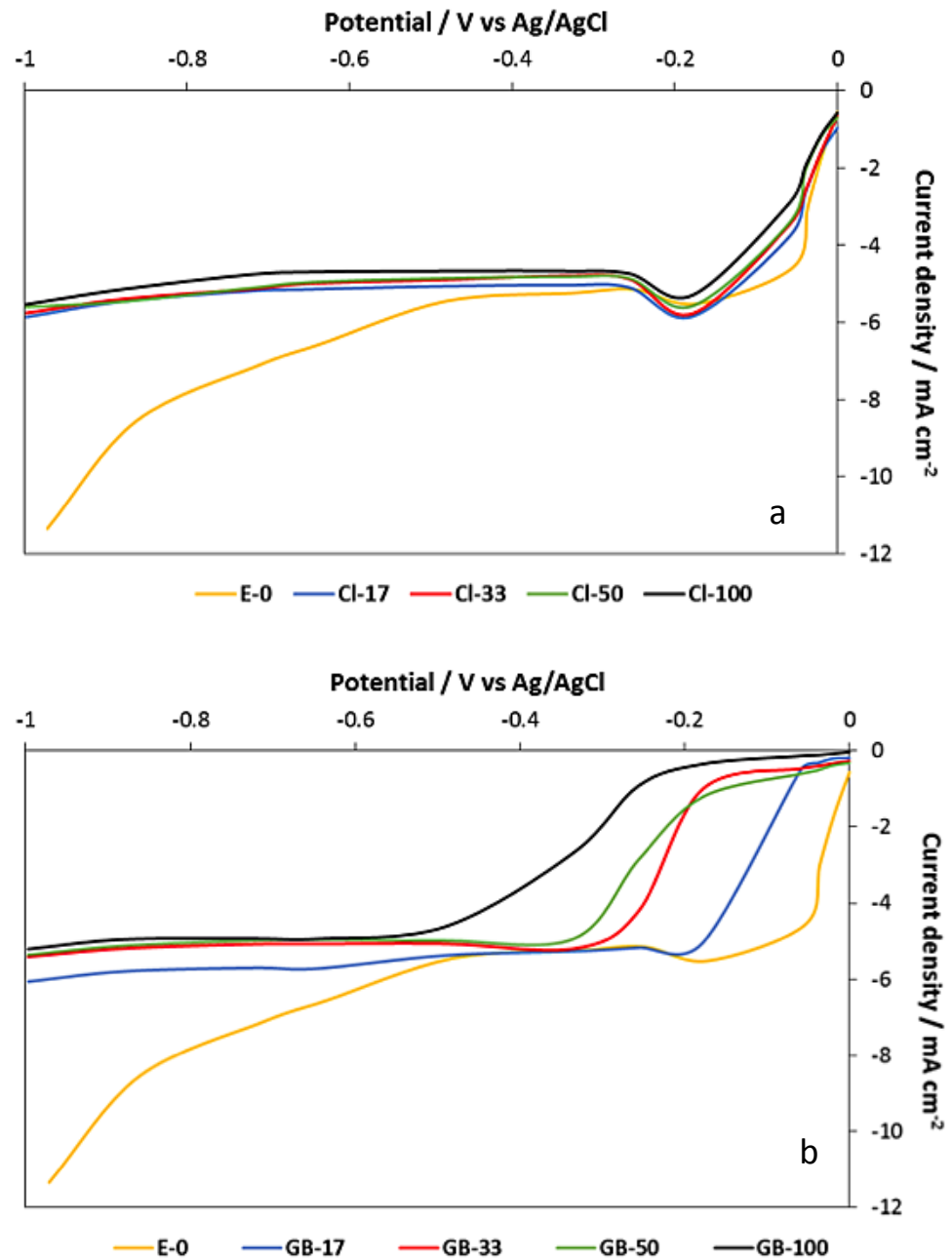

Potential / V vs Ag/AgCl

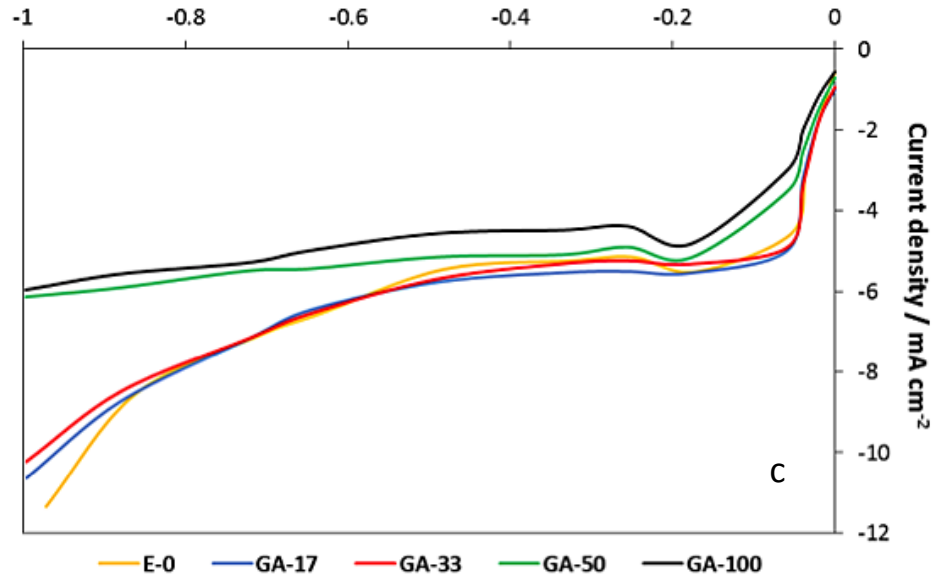

Figure 2: Cathodic polarisation curve for the EnFACE electrolyte without additives (E-0), and with different concentrations of single additives (a) $\mathrm{Cl}^{-}$(b) Copper Gleam B and (c) Copper Gleam A. Labels involving 17, 33, 50 and 100 refer to relative percentage with respect to the recommended dosage. 
Potential / V vs Ag/AgCl

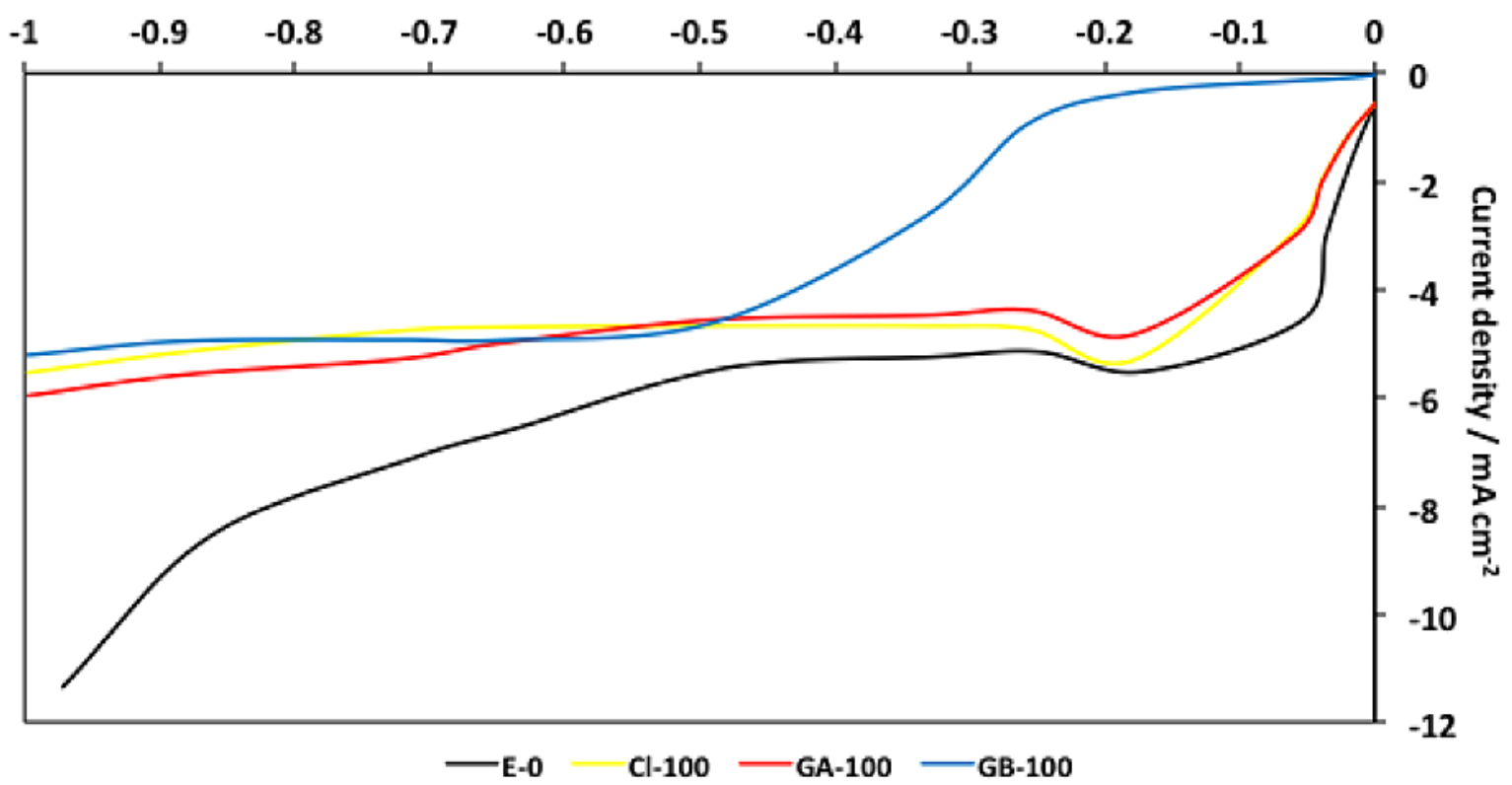

Figure 3: Cathodic polarisation curves of the EnFACE plating electrolyte i) without additives (E-0), and with single additives at recommended concentrations: ii) Copper Gleam B (GB100), iii) Copper Gleam A (GA-100) and iv) $\mathrm{Cl}^{-}(\mathrm{Cl}-100)$. 


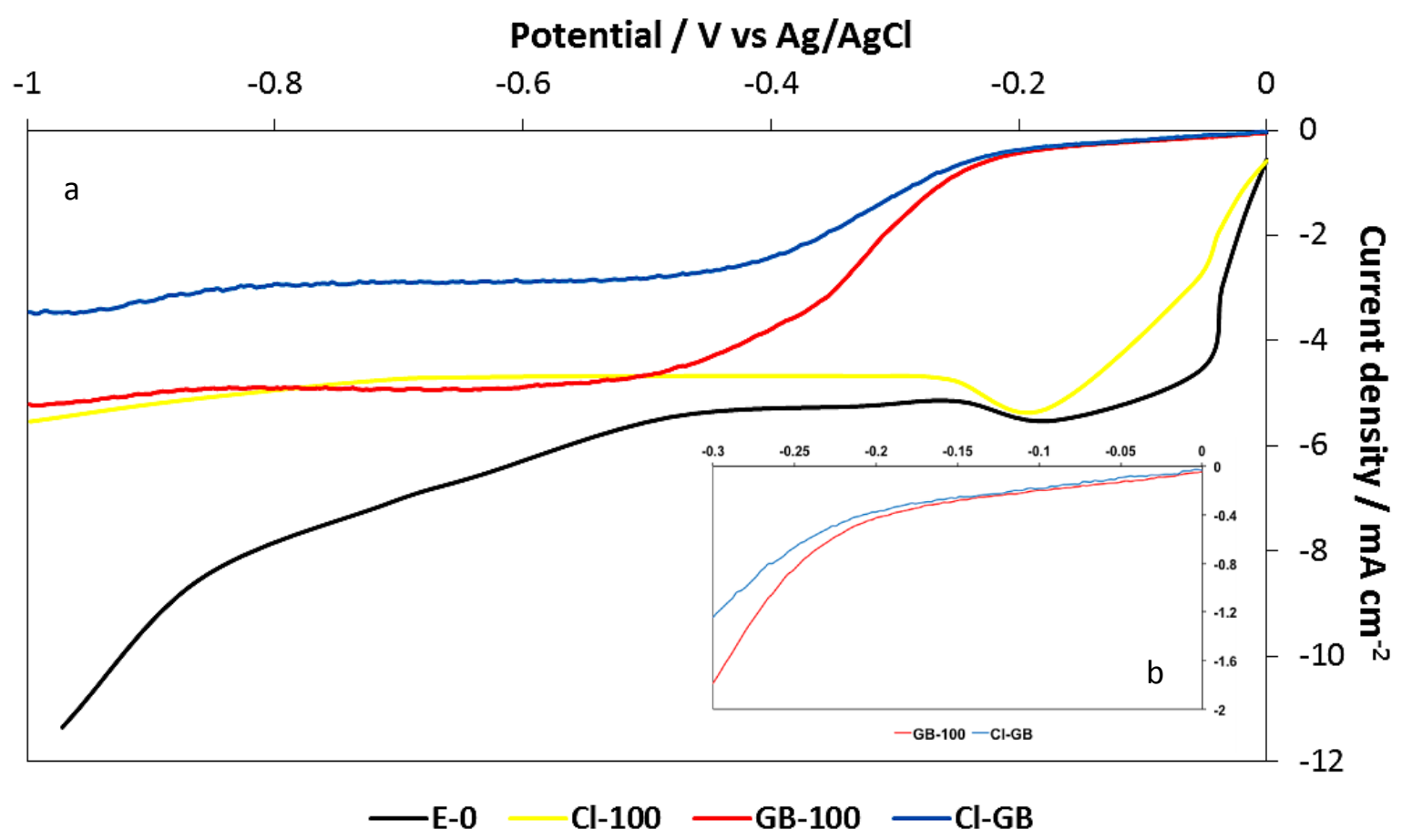

Figure 4: Cathodic polarisation curves of the Enface electrolyte: i) without additives (E-0),ii) with single additives $\mathrm{Cl}^{-}(\mathrm{Cl}-100)$ and Copper Gleam B (GB-100) at industry recommended dosages, and iii) with mixed $\mathrm{Cl}^{-}$and Copper Gleam B (Cl-GB). a) Plot showing potential range from 0 to $-1 \mathrm{~V}_{\mathrm{Ag} / \mathrm{AgCl}}$ and $\mathrm{b}$ ) inset, from 0 to $-0.3 \mathrm{~V}_{\mathrm{Ag} / \mathrm{AgCl}}$. 


\section{Potential / V vs Ag/AgCl}

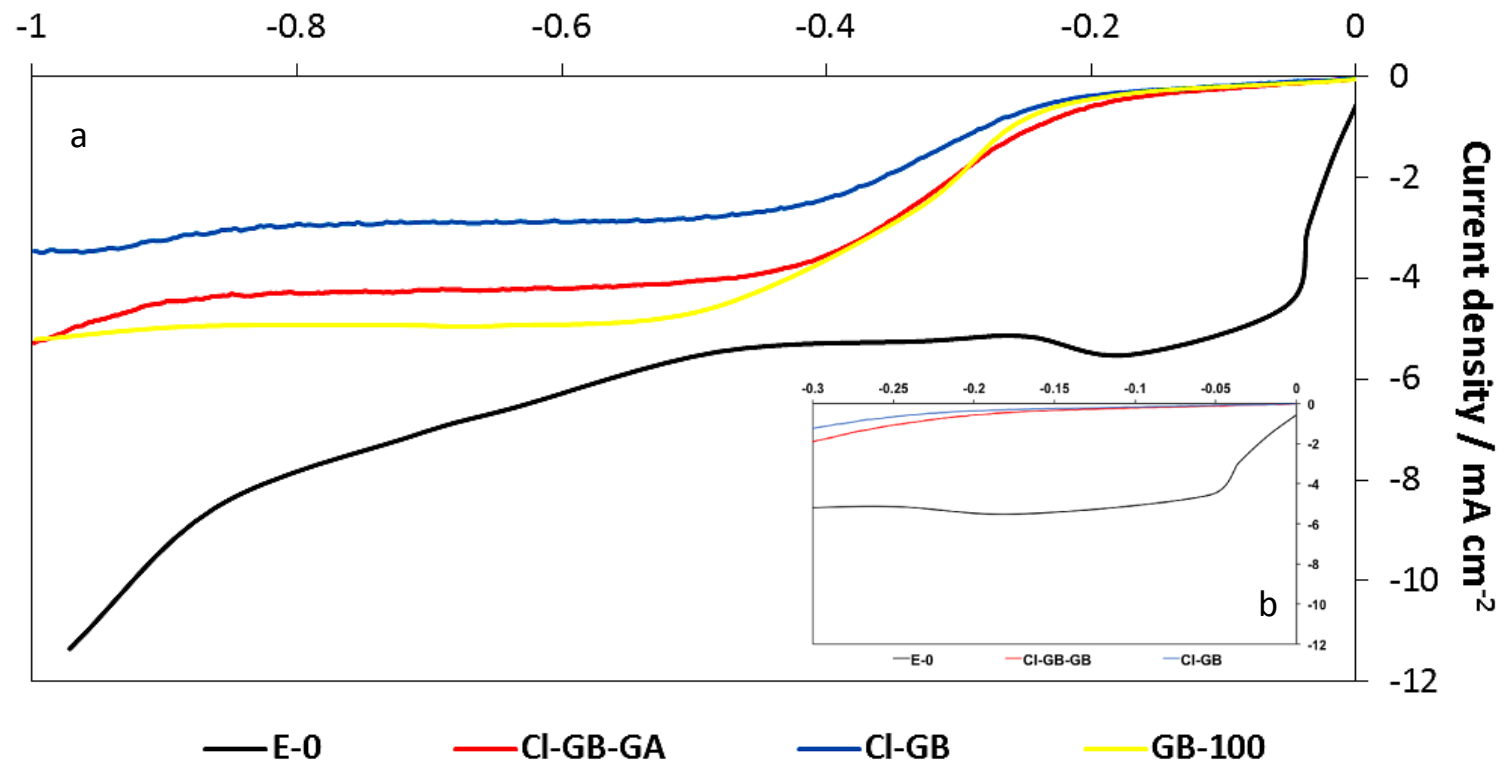

Figure 5: Cathodic polarisation curve of the EnFACE plating electrolyte: i) without additive (E-0), ii) with copper gleam B (GB-100), iii) with a mixture of Cl and Copper Gleam B (ClGB), and iv) with recommended concentrations of $\mathrm{Cl}^{-}$, Copper Gleam B and Gleam A (ClGB-GA). a) Plot showing overpotential range from 0 to $-1.0 \mathrm{~V} \mathrm{Ag} / \mathrm{AgCl}$ and $\mathrm{b}$ ) inset, at overpotential range of 0 to $-0.3 \mathrm{~V} \mathrm{Ag} / \mathrm{AgCl}$. 
Potential / V vs Ag/AgCl

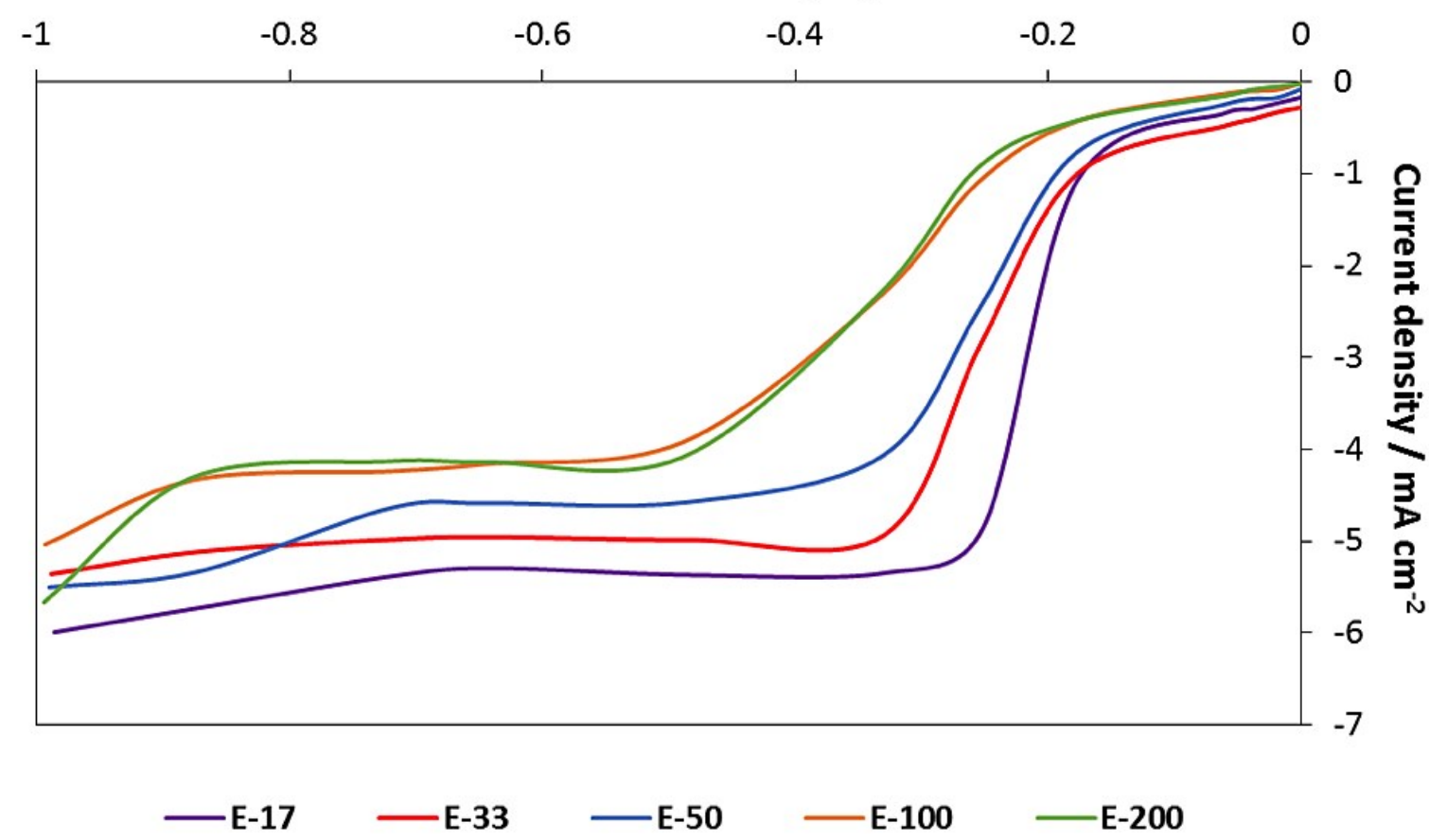

Figure 6: Cathodic polarisation curve of the EnFACE electrolyte with different concentrations of the mixed additives $\mathrm{Cl}^{-}$, Copper Gleam A, and Copper Gleam B. Labels involving 17, 33, 50, 100 and 200 refer to relative percentage with respect to the recommended dosage of $70 \mathrm{ppm} \mathrm{Cl}^{-}, 0.5 \mathrm{ml} / \mathrm{L}$ Copper gleam A, and $10 \mathrm{ml} / \mathrm{L}$ Copper gleam B. 